\title{
LAS PUNTAS SOLUTRENSES: DE LA TIPOLOGÍA A LOS ESTUDIOS FUNCIONALES
}

\section{The solutrean points: from typology to use-wear analysis}

\author{
Juan F. Gibaja ${ }^{1}$, Francisco J. Muñoz ${ }^{2}$, Carmen Gutiérrez ${ }^{3}$, Belén Márquez ${ }^{4}$ \\ e Ignacio Martín Lerma ${ }^{5}$
}

Recibido el 10 de abril de 2013. Aceptado el 29 de julio de 2013

Resumen. Este trabajo pretende ofrecer una imagen global de los estudios que se han realizado sobre un soporte tan particular y definitorio cronológica y territorialmente del Paleolítico superior como son las puntas solutrenses. Iniciaremos nuestro trabajo explicando los distintos tipos de puntas solutrenses que se han definido hasta el momento para posteriormente mostrar la información obtenida desde los estudios funcionales de las puntas arqueológicos y la surgida desde las réplicas experimentales. Ambas perspectivas complementarias serán el medio con el que hablar del grado de efectividad de las distintas puntas, los modos de enmangue, las fracturas que se producen como consecuencia de factores tanto funcionales y tecnológicos, así como aquellos generados como resultado de alteraciones mecánicas diversas. En todo caso, pretendemos aportar en qué punto estamos en esta temática más allá de la simple descripción morfológica.

Palabras Clave: puntas solutrenses, experimentación, análisis funcional.

Abstract. This paper aims to provide a comprehensive overview of the research on a particular category of tools that covers an important role as geographical and chronological marker: the Upper Paleolithic Solutrean points. Through a techno-functional approach we discuss the different typologies of Solutrean points in terms of degree of effectiveness, hafting modes, types of fractures produced by technological and functional factors, as well the use-wears traces caused by mechanical alterations. Our observations are based both on archaeological and experimental data. The objective of this article is to revise the state of art on this topic, presenting new technological and functional data that allow us to overcome a purely morphological approach.

Keywords: solutrean point, experimental practice, use-wear.

\section{PRESENTACIÓN}

Las puntas solutrenses son, por antonomasia, uno de los elementos más característicos del Paleolítico superior. Su diseño nos remite a un alto conocimiento de las técnicas de talla. Su morfología, cambiante a lo largo del espacio y del tiempo en el que transcurre el Solutrense, ha servido de base a innumerables contribuciones cientificas especialmente por el hecho de constituir un "fósil director" con el que apostillar una cronología relativa al contexto/nivel arqueológico al

(1) IMF-CSIC. Dpto. de Arqueología y Antropología. Carrer Egipcíaques, 15. E-08001 Barcelona 8España). jfgibaja@imf.csic.es

(2) Dpto. de Prehistoria y Arqueología. Universidad Nacional de Educación a Distancia. Paseo Senda del Rey, 7. E-28080 Madrid (España). fjmunoz@geo.uned.es

(3) Dpto. de Prehistoria y Arqueología. FF.LL. Universidad Autónoma. E-28049 Madrid (España).carmen.gutierrez@uam.es

(4) Museo Arqueológico Regional. Plaza de las Bernardas s/n. E-28801 Alcalá de Henares (Madrid, España). belen.marquez@madrid.org

(5) Dpto. Prehistoria, Arqueología, $\mathrm{H}^{\mathrm{a}}$ Antigua, $\mathrm{H}^{\mathrm{a}}$ Medieval y CCTT Historiográficas. Universidad de Murcia Campus de la Merced, E-30071 Murcia. ignacio.martin@um.es 
que están asociadas. Los distintos morfotipos definidos y su distribución espacial han permitido, junto a otras evidencias, abordar el estudio de las geografías sociales y las conexiones entre las distintas comunidades que las elaboraron. Todas estas aproximaciones, tanto desde una perspectiva diacrónica como sincrónica, han Ilenado, y siguen haciéndolo, páginas y páginas en revistas, libros y congresos (Ripoll 1994; Zilhao 1994; Straus 2001).

A los estudios centrados en la tipología, se han ido sumando en los últimos años otros aspectos que tratan de comprender de forma más amplia la cadena operativa. Así, han cobrado importancia los análisis sobre el origen de las rocas explotadas y las fuentes de aprovisionamiento. Del estudio pionero de los rasgos macroscópicos de las rocas perceptibles a simple vista (Zilhão 1997 para la Estremadura portuguesa, o de la Rasilla 1989 y Strauss y González 2009, entre otros, para el área cantábrica) se ha pasado en la actualidad a la aplicación de analíticas complejas que proporcionan mayor objetividad a los resultados (Aubry 1991; Aubry et al. 1998, 2007 para contextos solutrenses de Francia y Portugal).

Igualmente, junto a la diferenciación de los distintos procesos de talla y el grado de conocimientos técnicos requeridos, apoyados a menudo en la experimentación, han tomado fuerza los estudios dedicados a los remontajes como una vía más de aproximación a la tecnología (Muñoz 2000; Tiffagom 2004). Un claro ejemplo de la potencialidad de tales estudios son los diversos trabajos de investigación llevados a cabo en el asentamiento francés de Les Maitreaux (Aubry et al. 1998, 2004).

Dentro de esta visión global de la cadena operativa no puede faltar una aproximación funcional, pese a que el papel que han jugado hasta ahora los análisis traceológicos en el estudio de las puntas solutrenses ha sido muy escaso. Probablemente, esto pueda deberse a que se asume una función evidente basada en la morfología y, por lo tanto, la información obtenida y las interpretaciones propuestas no tendrían mayor recorrido explicativo. No obstante, las dudas nacen cuando se constata que los estudios traceológicos apenas han sido aplicados a yacimientos de cronología solutrense, independientemente de que hubiera o no puntas (Aubry et al. 1998). Los trabajos de Geneste y Plisson sobre diversos conjuntos franceses son pioneros en este sentido pero apenas han tenido continuidad hasta el momento. En ellos se plantea, por ejemplo, la propuesta del uso del arco en una fase tan antigua como el Solutrense (Geneste y Plisson 1986, 1990, 1993; Plisson y Geneste 1989). Sería deseable, a la vez que interesante, no sólo seguir trabajando sobre las distintas puntas solutrenses combinando la información morfológica, tecnológica y funcional, sino desde una perspectiva más amplia integrar estos datos y los referentes a otros útiles solutrenses en las propuestas interpretativas históricas sobre las comunidades humanas que vivieron en aquel periodo.

\section{LAS PUNTAS SOLUTRENSES EN LA PENÍNSULA IBÉRICA}

El Solutrense es un complejo industrial del SO europeo muy conocido pero no siempre bien estudiado. Dividido en diversas secuencias según cada región, podemos hablar de unas fases que, con distintos nombres, son comunes a este espacio tan amplio.

En Portugal, y más parcialmente en el SO francés, nos encontramos con una fase antigua denominada Protosolutrense, aunque algunos autores lo incluyen en la siguiente fase. El Solutrense inferior continúa en la zona francesa y abarca al levante español. En estos momentos iniciales surgen algunas novedades técnicas que buscan elementos foliáceos apuntados desde distintas técnicas. Estos elementos son la punta de Vale Comprido, derivada de una secuencia técnica de lascado específica, y la punta de cara plana, obtenida mediante retoques planos sobre una de las caras. Esta segunda punta alcanzará mayor éxito apareciendo distribuida por toda la zona geográfica solutrense durante las etapas inferior y media, siendo muy rara en el Solutrense superior.

A lo largo del Solutrense medio se consolida el uso del retoque plano, extendiéndose en amplias superficies de ambas caras en lo que se conoce como bifacialidad. Es en este momento, además, cuando la cornisa cantábrica se incorpora a este mundo. Vemos surgir una punta más elaborada y espigada conocida como hoja de laurel que alcanzará a todos los rincones del complejo solutrense.

Hacia finales del Solutrense medio, la hoja de laurel se diversifica en distintos subtipos que se desarrollarán en la fase superior y en el Solutrense superior evolucionado mediterráneo. Son múltiples variantes de este tipo relacionadas con la forma de la base - cóncava, convexa, recta, pedunculada, con muesca- y el eje de simetría, entre ellas las puntas de muesca $y$, con carácter regional, los foliáceos asimétricos de Montaut y Serinyá, así como las puntas de base cóncava cantábricas.

Otros tipos nuevos son las hojas de sauce, máxima estilización de las puntas de laurel que surgen junto a conceptos originales de punta como la de aletas y pedúnculo. Esta es la última fase de expansión de las puntas bifaciales con retoque plano que ofrecen una amplia gama de soluciones técnicas. En la base de esta diversidad se documentan novedades como el retoque a presión junto a la percusión en piedra blanda y la aplicación del tratamiento térmico para mejorar la calidad del soporte ante la talla.

Durante el Solutrense terminal, final y Solutrense superior evolucionado, el retoque plano y la bifacialidad van perdiendo peso a favor de otros modos técnicos conocidos anteriormente como el retoque abrupto, entrando en lo que se ha venido en llamar proceso de "desolutreanización". Es ahora el momento de expansión de otros tipos de puntas, como la de muesca mediterránea, o su sustitución por hojitas de dorso en el área francesa y cantábrica. 


\subsection{Las puntas unifaciales del Protosolutrense y Solutrense inferior}

\subsubsection{Puntas de Vale Comprido}

Una variante especifica de las puntas de cara plana son las denominadas puntas de Vale Comprido (Fig. 1: 1). Se desarrollan dentro del proceso de creación de elementos líticos de proyectil que sucede entre finales del Gravetiense e inicios del Solutrense, aunque su producción sistemática parece posterior a 22000 BP (Zilhâo et al. 1999: 171).

Elaboradas sobre láminas o lascas laminares, se obtienen de núcleos prismáticos mediante percutor de piedra blanda dentro de una cadena operativa unipolar recurrente. Ofrecen una forma triangular apuntada con talones espesos y ondas marcadas. Para conseguir el adelgazamiento de la base, una vez extraída la pieza, se regulariza el talón en la

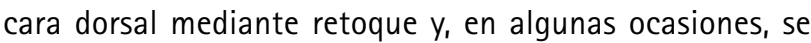
acompaña de la eliminación del bulbo. En varias de las puntas se observan también retoques -a veces planos- sobre los bordes, llegando a delineaciones denticuladas en los casos más extremos. La presencia o no de retoques en los bordes laterales ha servido de base para una clasificación en tres subtipos que, en opinión de Zilhâo y Aubry (1995: 134) representarian, más bien, el ciclo de uso, reavivado y abandono, en vez de variabilidad interna.

A diferencia de las puntas de cara plana, en las de Vale Comprido, la regularidad morfológica parece provenir del sistema de lascado y no de la aplicación del retoque plano sobre amplias zonas de la superficie dorsal y, puntualmente, de la ventral. Sin embargo, ambas comparten el recurso del retoque para el adelgazamiento de la zona proximal. Su función como puntas de proyectil ha sido deducida por la presencia de fracturas en lengüeta y burinantes en el ápice distal (Zilhâo y Aubry 1995: 134).

Estas puntas han sido definidas en el Protosolutrense portugués, más concretamente en el yacimiento epónimo de Vale Comprido-Encosta, aunque están presentes en un amplio espectro de sitios en torno a la Estremadura portuguesa como: Terra do Manuel, Grotte de Caldeirâo (niv. I y Ja), Vascas, Cova da Moura, Salemas, Furadouro, Almonda, Picareiro, Anecrial, Buraca Escura y Buraca Grande (Zilhâo et al. 1999). Piezas similares han sido localizadas en algunos yacimientos franceses de la Dordoña (Laugerie-Haute Est (capa 31) y l'Abri Casserole (niveles 9 y 10) y L'Ardèche (Solutrense inferior de La Baume d'Oullins) (Zilhâo y Aubry 1995). Al tratarse de so-

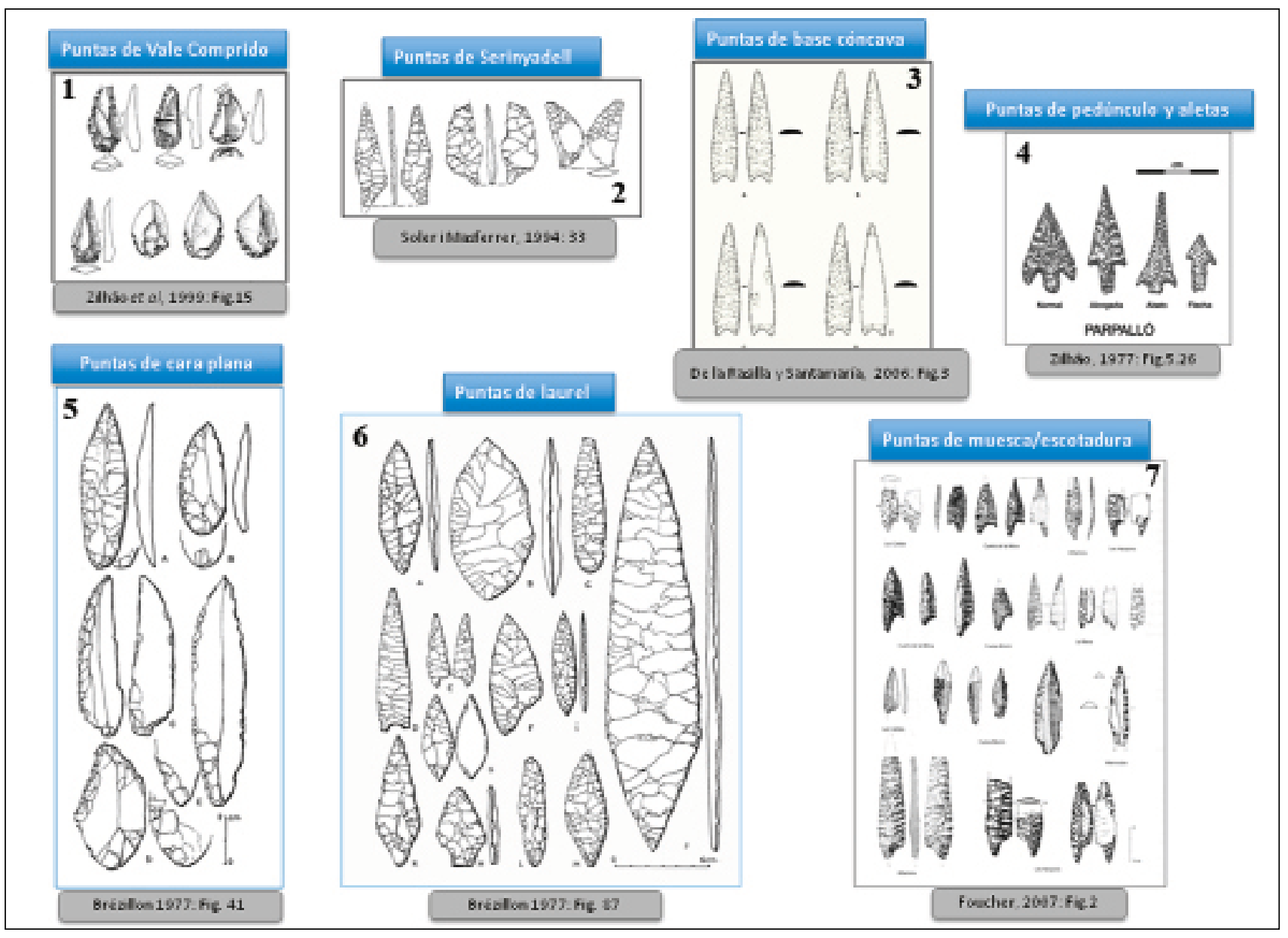

A Figura 1. Representación de algunos de los tipos de puntas citadas en el texto. 
portes que no siempre presentan retoques convencionales, es posible que una revisión más exhaustiva de conjuntos líticos de cronología contemporánea en otras zonas peninsulares descubra una distribución más amplia.

No obstante, la existencia de este Protosolutrense peninsular ha sido cuestionada por diversos autores como de la Rasilla y Llana (1995) o Muñoz (2010), incidiendo en el hecho de que el retoque que presentan estas puntas casi nunca es plano y en ningún caso profundo o invasor.

\subsubsection{Puntas de cara plana}

Sonneville-Bordes y Perrot (1954: 334) las definen como una pieza foliácea simétrica o asimétrica, con un extremo apuntado (punta de cara plana) u obtuso (hoja de cara plana), con retoques planos que cubren total o parcialmente la cara superior, sobre todo la base, la punta y uno de los bordes, aunque a veces se presentan también en la cara inferior, denominada plana, retoques en la base y en la punta (Fig. 1: 5). Smith (1966), tras considerar las anteriores definiciones como imprecisas y contradictorias, diferencia cinco subtipos: piezas simétricas (A), en forma de gota (B), similares a la punta de chatelperron (C), anchas y sobre lasca (D), en forma de lámina apuntada (E).

Entre todos los autores que contemplan una lectura tecnológica, destaca Zilhão (1997: 212) que en yacimientos de Portugal, como Vale Almoinha o Casal do Cepo, ha constatado el predominio del subtipo $B$ dentro de una secuencia basada en el acondicionamiento de la base, la eliminación del bulbo y la modificación de la morfología mediante retoque plano en las zonas mediales de los bordes. Finalmente se aplica el retoque al extremo distal.

Las diferentes características de este tipo inducen a pensar que se trata de piezas donde, sobre lasca y sobre lámina, se han ensayado diversas fórmulas para obtener una pieza adelgazada y homogénea tanto en el grosor de ambos laterales como, con menos fortuna, en su simetría. Generalmente, las más antiguas están hechas sobre hojas y lascas de un grosor mayor y mantienen la simetría solo cuando los retoques cubren casi todo el anverso. Paulatinamente, se escogen soportes más delgados, tienen contornos más regularizados y retoques en el reverso, fundamentalmente para adelgazar la zona bulbar, con una fuerte tendencia a transformarse en piezas bifaciales.

\subsection{Las puntas bifaciales del Solutrense medio y superior}

\subsubsection{Hojas de laurel}

Esta etapa aparece dominada por las hojas de laurel que presentan morfologías muy variadas, entre las cuales, algunas reciben nombres distintos en función de su distribución geográfica. A pesar de su extremo apuntado, son conocidas como hojas de laurel, en vez de puntas, por la silueta que adoptan la mayor parte de los ejemplares. Su superficie aparece cubierta por retoques planos, invasores y bifaciales. Aunque se conocen ejemplares unifaciales o incluso otros en que el retoque en la cara ventral afecta solo a las zonas de la punta y/o la base, por ejemplo en los niveles del Solutrense medio de las Caldas y la Riera (Corchón y Cardoso 2005: 100), estos proyectiles realmente serian puntas de cara plana en donde paulatinamente se incorpora el retoque plano en el reverso.

Realizadas sobre lasca laminar o lámina procedentes de núcleos de distinto tipo, las técnicas de extracción y retoque parecen haber seguido procedimientos diversos. Algunas puntas pequeñas han podido ser obtenidas a partir de lascas o láminas gruesas con percutor duro para las primeras fases de lascado (Fig. 1: 6). El retoque sería ejecutado con percusión directa con percutor orgánico blando (Aubry et al. 2007: 110). En la revisión del material de Almoinha, Maillo Fernández (1999: 196) constata una última fase de retoque a presión con compresor blando como ya habian avanzado Sonneville-Bordes y Perrot (1954: 334).

Hay evidencias de tratamientos térmicos para mejorar las cualidades de la materia prima antes del retoque durante el Solutrense medio de Caldeirão, Lapa do Anecrial y Vale Almoinha (Zilhâo 1997: 216) y superior de Caldeirão, Laugerie-Haute y Parpalló (Tiffagom 1999: 80).

A finales del Solutrense medio, y especialmente en el superior, se documenta una fuerte variedad de morfologías de este tipo que ya fue recogida por Smith (1966) en la creación de 13 subtipos. Hemos agrupado estos subtipos de la siguiente manera: puntas simétricas apuntadas en los dos extremos (tipos A normal y $B$ ancha), punta de base convexa (C), puntas de base cóncava (simétrica $\mathrm{D}$ o asimétrica $\mathrm{E}$ ), puntas asimétricas (asimetria ligera $\mathrm{M}$ y de tipo Montaut o de muesca oblicua F, asimilable a las puntas de Serinyadell), punta de Badegoule bifacial $(G)$, punta de pedúnculo $(H)$, punta de laurel miniatura (I), punta muy grande $u$ hoja de Volgu (J), punta de base triangular (K), punta alargada y simétrica de bordes paralelos y extremos apuntados o redondeados (L).

De todas ellas vamos a destacar, por su distribución geográfica peninsular localizada, las puntas de Serinyadell desde el Solutrense medio y las puntas de base cóncava en el Solutrense superior.

Esta diversidad morfológica responde, en la mayoría de los tipos, a intentos o ensayos de crear un elemento de enmangue netamente destacado que facilite la inserción de estos proyectiles bifaciales en el astil. Las diferentes soluciones de enmangue tienen una distribución geográfica bastante definida y probablemente constituyen diferentes soluciones técnicas a un mismo problema.

\subsubsection{Puntas de Serinyadell}

Presentan una silueta ovalada con retoque plano y bifacial (Fig. 1: 2). Tienen el extremo distal muy aguzado y 
los bordes de la mitad superior del soporte formando un ángulo agudo. A medida que se llega al extremo proximal estos bordes dejan de ser simétricos. En la base presenta un pedúnculo que no sigue el eje de simetría de la pieza. El borde izquierdo se curva ligeramente hacia adentro formando una concavidad larga y casi vertical, mientras que el borde derecho es recto casi desde la base hasta que se dobla hacia adentro formando una concavidad transversal que da origen a un pedúnculo triangular. Este elemento es puntiagudo aunque en ocasiones puede conservar el plano de percusión y aparece desviado hacia un lado. Se desarrollan durante el Solutrense medio y se asocian al núcleo de Serinyá, en Cataluña, apareciendo principalmente en los yacimientos de Reclau Viver, l'Arbreda y Davant Pau (Soler 1994: 35).

Se ha señalado también su proximidad morfológica con algunas hojas de laurel de pedúnculo desviado de la cornisa cantábrica, en el Solutrense medio y superior de las Caldas -niveles 17 y 8-, Morín y nivel D de Bolinkoba, en Monte Fainha (Portugal) y en el Périgord francés (Laugerie-Haute, Sous Champs y Solutré), (Corchón 2008:199). Igualmente para Fouche restos foliáceos de Serinyadell, próximos a las puntas de Montaut, configuran un grupo de puntas asimétricas que se expanden desde el País Vasco por el ámbito pirenaico hasta Cataluña, documentándose tanto en yacimientos al aire libre como en cueva o abrigo (Foucher 2007: 283).

\subsubsection{Puntas de base cóncava}

Este tipo de punta se define por la hendidura que presenta en su base y que configura su característica silueta (Fig. 1: 3). La concavidad, realizada mediante retoque abrupto, facilita el adelgazamiento de la base $y_{1}$ en consecuencia, su enmangue. Este recurso técnico ofrece una solución óptima a las piezas manufacturadas sobre lascas laminares de talón espeso, especialmente las fabricadas en cuarcita. Se van configurando mediante el retoque a presión. De la Rasilla y Santamaria (2005: 151) han destacado que el retoque plano cubre toda la superficie de las piezas realizadas en sílex y algunas en cuarcita, si bien, sobre esta última materia es más habitual retocar únicamente la cara superior y levemente la base de la inferior, aunque a veces se añade algún retoque de regularización en otras zonas de esta cara cuando la cuarcita no es de buena calidad. Esta ausencia de retoque sobre la cara ventral de las puntas de cuarcita se debe a que las caras inferiores son más planas al carecer de rotura concoide.

Las puntas de base cóncava se distribuyen durante el Solutrense superior por la cornisa cantábrica, penetrando en Pirineos y SO francés. El yacimiento más oriental es el de la Fuente del Trucho (Huesca). A lo largo de este territorio hay un cambio importante de la materia prima. En Asturias predomina el uso de la cuarcita de grano fino, en Cantabria cuarcita y sílex son empleadas aproximadamente en igual medida y en el País Vasco y Francia se utiliza exclusivamente el sílex (de la Rasilla y Santamaría 2005: 153-154).

\subsubsection{Hojas de sauce}

Estas puntas aparecen en escaso número pero con amplia distribución geográfica por la Península Ibérica y Francia durante el Solutrense superior. Más estilizadas que las hojas de laurel, ofrecen una técnica más depurada. Este foliáceo, realizado sobre hoja, es alargado, de bordes paralelos y de sección semicircular o triangular. Presenta un retoque por presión muy regular, paralelo entre sí y perpendicular al eje longitudinal del soporte. Generalmente es unifacial, excepto para corregir irregularidades en su cara ventral: supresión del bulbo y regularización de la punta. La variabilidad de este tipo, referida a la morfología de la base, tamaño y extensión del retoque, no ha sido plasmada por Smith en sus diferentes subtipos (1966: 54).

\subsection{Las "puntas ligeras" del Solutrense superior, final, terminal y superior evolucionado}

En muchas ocasiones los términos "punta de proyectil o punta ligera de proyectil" se ha usado como un eufemismo ante la imposibilidad de establecer una interpretación funcional precisa, es decir, punta de flecha o punta de venablo. En este sentido, los tipos que aparecen en el Solutrense (punta de aletas y pedúnculo, punta de muesca de retoque plano y punta de muesca de retoque abrupto) son susceptibles de ser propulsados con arco.

\subsubsection{Puntas de muesca}

Desde el punto de vista tipológico, esta categoría conforma dos grandes grupos: las de retoque plano, localizadas sobre todo en la franja franco-cantábrica, y las de retoque abrupto, típicas de la zona mediterránea. La presencia de los dos tipos se constata en un mismo yacimiento, Gruta de Salemas (Zilhão 1997: 647 y ss.). La mezcla de elementos de ambas regiones podría llevarnos a dudar del valor de marcador étnico de estas puntas y considerar su presencia como soluciones estilisticas usadas indiferentemente con una misma función, o de una forma muy exclusiva, con funciones diferentes (Plisson y Geneste 1984; Chadelle et al. 1990).

La punta de muesca de retoque abrupto constituye un elemento característico del final del Solutrense en el levante peninsular. Aparece desde el Solutrense superior y es especialmente abundante en el Solutrense superior evolucionado. Está realizada sobre hoja y se caracteriza por tener un retoque abrupto en el dorso opuesto a la muesca que no necesariamente ocupa todo el borde. El pedúnculo está formado por una muesca con retoque también abrupto. En algunas ocasiones, la pieza tiene un retoque simple en el otro borde. Aunque Tiffagom (2006: 17) propone su ori- 
gen en las puntas/cuchillo del Gravetiense central y del este europeo, que llegarian al Mediterráneo peninsular por contacto con el Salpetriense francés, es bastante más plausible entender su reaparición dentro del fenómeno de desolutreanización o pérdida del retoque plano y la vuelta a las tradiciones gravetienses firmemente asentadas en el territorio valenciano.

La punta de muesca de retoque plano está realizada sobre una hoja generalmente estrecha y plana aunque también hay ejemplares menos estilizados. El retoque invasor, realizado por presión, forma la punta mediante extracciones paralelas. Estos levantamientos generalmente son unifaciales o el retoque del reverso es bastante parcial. La muesca se realiza en el extremo proximal con un retoque abrupto. La longitud y anchura del soporte disminuye muy poco durante el proceso de talla (Fig. 1: 7).

Tanto en la cornisa cantábrica como en el litoral mediterráneo las puntas de muesca, con diferentes soluciones técnicas de fabricación, muestran, junto con la puntas de aletas y pedúnculo, la necesidad de crear proyectiles con enmangues más sólidos y diferenciados de la punta, que probablemente estén relacionados con nuevos sistemas de enmangue y propulsión.

\subsubsection{Puntas de aletas y pedúnculo}

Presentan un fuste con una clara tendencia triangular cubierta por un retoque plano e invasor, que en la mayoría de las ocasiones es bifacial. Las aletas están bien marcadas y diferenciadas de la punta, al igual que el pedúnculo central (Fig. 1: 4). Se fabrican sobre lascas y hojas alargadas y delgadas o bien lascas espesas y grandes. La cadena operativa de fabricación es similar a la de las hojas de laurel. Primero se realiza una reducción bifacial mediante percusión directa con percutor duro o blando para adelgazar el soporte, eliminar los restos de córtex y los abultamientos en la zona central del anverso. Posteriormente, la talla directa con percutor duro o blando es sustituida por un presionador de mano para obtener la preforma. Por último, se destaca el pedúnculo, se terminan de elaborar las aletas y se conformar la silueta final de la pieza (Muñoz 2000).

En esta punta es fundamental la descripción y análisis de las aletas como atributo característico de este proyectil y elemento básico para el sistema de enmangue. Su tipometria y morfología determinarán en gran medida su funcionalidad, ya sea por el hecho de funcionar como tope entre la punta y el pedúnculo o porque reduce el rozamiento durante la penetración del astil. Su estudio se hace de forma individualizada, aleta izquierda y derecha, posicionando el proyectil con la cara dorsal hacia arriba.

Se han determinado tres tipos característicos de aletas: en ángulo recto y en ángulo agudo, o triangulares, con respecto al borde longitudinal del pedúnculo (Hugot 1957), en forma de gancho y hemiovaladas. En el primer caso, el extremo proximal y lateral de la punta forma con el inicio del pedúnculo un ángulo de unos $90^{\circ}$ aproximadamente.

Las aletas triangulares constituyen una prolongación de los bordes de la punta que se unen con el extremo distal del pedúnculo formando un ángulo agudo. Las morfologías en gancho son una variante de la anterior, pero en lugar de ser una prolongación de los filos de la punta se produce una pequeña inflexión en la unión de ésta con la aleta, que adopta una forma convexa que le otorga esta morfología característica y que en algunos casos es muy pronunciada. Por último, las aletas hemiovaladas son también una variante de las triangulares, en las que el extremo distal no es puntiagudo sino casi semicircular (Muñoz 2000).

A las viejas ideas que relacionaban el Solutrense peninsular con el Ateriense africano se han unido recientemente los argumentos de Tiffagom (2005: 73) quien apoya una influencia del complejo africano en momentos avanzados del Solutrense mediterráneo a partir del descubrimiento de elementos Levallois y el desarrollo de las puntas de pedúnculo y aletas. Estos argumentos han sido contestados por Alcaraz (2007) señalando, entre otros aspectos, la importante distancia cronológica entre ambos conjuntos.

\section{LA IMPLICACIÓN DE LA TRACEOLOGÍA EN EL ESTUDIO DE LAS PUNTAS SOLUTRENSES: LOS PROGRAMAS EXPERIMENTALES}

La relevancia de los estudios tipológicos sobre las distintas puntas solutrenses definidas para la Península Ibérica y las implicaciones de carácter cronológico y "cultural", no han tenido su correlato en relación a su uso, grado de efectividad, potencialidad, etc. A este respecto, los dos trabajos que hasta ahora han sido un continuo referente en el ámbito europeo son los publicados por J. M. Geneste y H. Plisson, con respecto a las puntas con muescas, y por F. J. Muñoz y B. Márquez para las puntas con pedúnculo y aletas. Aunque sus resultados son enormemente interesantes, se han centrado únicamente en aquellas puntas representadas en los yacimientos sobre los que estaban trabajando. Ello nos da una idea de la importancia de sus trabajos, pero a la vez del vacío que existe con respecto al resto de puntas descritas en el apartado anterior.

En todo caso, vamos a explicitar los resultados a los que se llegaron con tales experimentaciones, ya que algunos datos podemos extrapolarlos al resto de puntas solutrenses.

\subsection{Los trabajos de J.M. Geneste y H. Plisson con puntas de muesca}

Como hemos apuntado al inicio de este trabajo, la ingente bibliografía generada sobre los aspectos formales y 
tipológicos de los instrumentos líticos solutrenses, con especial atención sobre las puntas, contrasta con el escaso interés que han suscitado los estudios traceológicos como medio para conocer las actividades a las que se destinaron tales útiles.

En el caso de las puntas, objeto de estudio de este artículo, de manera recurrente se ha acudido a diversos trabajos impulsados por J. M. Geneste y H. Plisson desde finales de los 80. Sin duda, pusieron las bases de cómo un estudio interdisciplinar puede generar un volumen de información enorme sobre cuestiones tan diversas como las estrategias de caza implantadas, la funcionalidad de los asentamientos o la efectividad de las distintas puntas (Geneste y Plisson 1986, 1990, 1993; Plisson y Geneste 1989).

Un amplio estudio morfo-tecnológico y funcional, acompañado y contrastado con réplicas experimentales, de puntas de muesca solutrenses de los yacimientos franceses de Placard, Fourneau du Diable, Pech de la Boissière y Combe Saunière, les permiten distinguir entre las fracturas producidas por impacto y las generadas por accidentes de talla o intencionalmente. Concluyeron diciendo que tales puntas eran objetos especializados, no usados para otra función distinta que la de servir como armaduras de proyectil ligeras.

Los resultados de la observación de las piezas arqueológicas y experimentales coinciden en algunos aspectos, como por ejemplo en lo que se refiere a las burinaciones que están totalmente ausentes en los casos de accidente de talla. En este caso, las fracturas en lengüeta son también poco numerosas y muy cortas, al contrario de lo que se observa en las usadas como proyectiles.

Este trabajo se centró especialmente en las fracturas macroscópicas, en tanto que la mala conservación del material no permitía un análisis microscópico dirigido a detectar y reconocer estrías de impacto.

A partir de sus características morfométricas, propusieron que la mayoría de las puntas de muesca pudieron estar montadas sobre astiles de entre 8 y $9 \mathrm{~mm}$ de diámetro. Pero además, valorando su peso las dividieron en dos grandes grupos: las más pequeñas, entre 2-11 gr con una media de $4,3 \mathrm{gr}$ y un diámetro de $8-9 \mathrm{~mm}$, y otras mayores entre 12-15 $\mathrm{mm}$ con pesos superiores a $8 \mathrm{gr}$. Estas diferencias en longitud y peso les llevan a pensar que mientras las más pequeñas pueden incluirse en el rango de las puntas de flecha, las más grandes pudieron utilizarse enmangadas para utilizarlas mediante otro tipo de elemento de propulsión. Propuesta que sostienen acudiendo a múltiples ejemplos etnográficos en los que tanto el peso como el tamaño de la punta para propulsión con arco coinciden con los las puntas de tales yacimientos (media inferior a $4 \mathrm{gr}$ ).

El porcentaje de piezas con fracturas de impacto en las puntas arqueológicas (44\%) difería de las empleadas experimentalmente (26\%). Ello lo atribuyen no sólo al proceso artificial del programa experimental, sino especialmente a las diversas técnicas de enmangue y sistemas de fijación que pudieron tener una influencia significativa, y no fueron suficientemente exploradas experimentalmente. Tanto es asi que muchas de las roturas en la parte medial de las puntas, que difícilmente se documentaban durante los procesos de talla, debieron producirse, en gran parte, por su mala fijación al astil. Las ligaduras, cuando no están bien sujetas, suelen producir numerosas fracturas, de diferente morfología y a menudo localizadas en la zona no cubierta por el enmangue.

Cuando analizaron el grado y el lugar donde se produjo la fracturación de las puntas, propusieron que los conjuntos arqueológicos parecian estar compuestos por puntas rotas durante la caza y puntas rotas en otros momentos. Concretamente las partes apicales localizadas en los yacimientos debian de venir incluidas dentro de las carcasas, porque si no, se pierden en el campo al fracturarse. Las proximales, por su parte, entrarían a los yacimientos insertas aun en los astiles. El hecho de que aparezca una proporción relativamente grande de partes apicales en Combe Saunière (24,5\%) y en Placard (34\%) indicaría que se transportaba el animal entero al yacimiento. Este discurso les lleva a hablar finalmente de que estos yacimientos debieron ser lugares temporales y especializados de caza.

\subsection{Los trabajos de F. J. Muñoz y B. Márquez con puntas de aletas y pedúnculo}

La punta de aletas y pedúnculo constituye uno de los elementos distintivos por los que se caracteriza el Solutrense extracantábrico. La morfología que presentan estos proyectiles ha contribuido a fijar la hipótesis de su posible funcionalidad como puntas de flecha para ser propulsadas con arco. Pero hasta hace relativamente poco tiempo, (Muñoz 1998, 1999, 2000; Márquez y Muñoz 2003, 2008; Muñoz y Márquez 2006), no existía un programa experimental para caracterizar este instrumental desde el punto de vista tecnológico, funcional, balístico y cinegético. El trabajo con réplicas experimentales de arcos y flechas prehistóricos, con un comportamiento balístico y cinegético óptimo, permite pensar que el origen del arco fue anterior a lo que tradicionalmente se había pensado.

En este programa experimental, las variables que se controlaron fueron:

- Tipo de arco.

- Potencia del arco.

- Apertura del arco en el momento del disparo.

- Peso de la punta.

- Peso del astil.

- Longitud del astil.

- Número de plumas de la flecha.

- Longitud del área emplumada.

- Ángulo de las plumas con el astil. 
- Longitud total de la flecha.

- Peso total de la flecha.

- Velocidad inicial del disparo.

- Velocidad de impacto.

- Trayectoria del vuelo de la flecha.

Para el estudio balístico, el experimento contó con un total de 47 flechas, con una longitud total que oscila entre 74,2 y $137 \mathrm{~cm}$ y un peso entre 21,6 y $92,5 \mathrm{~g}$. Los astiles empleados eran varillas cilíndricas de madera industrial de cedro, haya y roble, oscilando su diámetro entre los 8 y los 10 mm (Muñoz y Márquez 2006) (Fig. 2).

Para el emplumado se han utilizado plumas de buitre y alimoche, unidas al astil con pelo de caballo. El número de plumas oscila entre dos y tres para los astiles más cortos. Los estabilizadores de cuatro elementos se han reservado para los astiles más largos, a partir de $130 \mathrm{~mm}$. La longitud de la zona emplumada varía entre los 12 y los $20 \mathrm{~cm}$ Mientras que la anchura de la pluma, una vez cortada, se sitúa entre 1 y $4,5 \mathrm{~cm}$. El ángulo de emplumado, formado por el astil y el inicio de la pluma en su parte distal, presenta valores que van desde los $106^{\circ}$ a los $155^{\circ}$. Esta variación responde a si la pluma ha sido o no cortada.

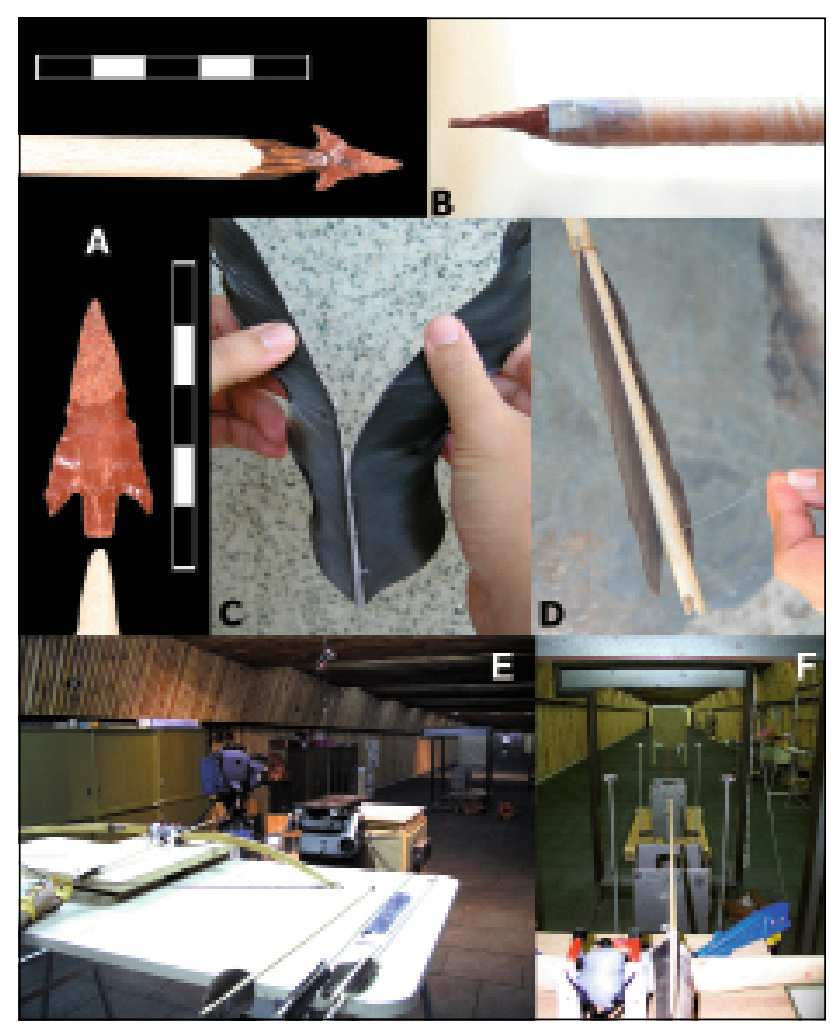

A Figura 2. Desarrollo de la experimentación balística. Cajeado practicado a los astiles para la inserción de las puntas y punta ya engastada y aplicada la resina: A. Proceso de refuerzo del astil y sujeción de una punta mediante tripa fresca de cordero: B. Montaje de las plumas con ayuda de pelo de caballo: C y D. Bastidor utilizado para fijar los arcos: E. Aparato medidor de velocidad empleado, con las dos células: F.
El culatín se generó mediante una ranura en el extremo proximal de la flecha, cuya orientación es siempre contraria a la que presenta el cajeado de la punta.

Sobre estos astiles se montaron réplicas de puntas de aletas y pedúnculos de los niveles solutrenses del yacimiento de La Cueva de Ambrosio. En total se escogieron 12 ejemplares procedentes de Solutrense superior evolucionado, Solutrense superior y Solutrense sensu lato

Para su fabricación se utilizaron moldes bivalvos en silicona de alta resolución. Este sistema de trabajo permitió reconstruir la morfología original de aquellas piezas que presentaban pequeñas fracturas. Los moldes se rellenaron con resina de poliéster. Para obtener un peso idéntico al original dicha resina fue cargada con polvo de mármol (marmolina) y óxido de hierro pulverizado (ocre). Los pesos de las puntas oscilan, según los tipos, entre los 0,40 y los 4,60 g y su longitud total entre los 20 y los $51 \mathrm{~mm}$.

Estas puntas, insertadas en los astiles mediante un cajeado en el extremo distal de los mismos, fueron fijadas con una almáciga formada por resina de pino (50\%), cera de abeja (30\%) y ocre $(20 \%)$ como aglutinante para formar una mezcla homogénea parecida al lacre. Una vez que esta mezcla empieza a endurecerse, el enmangue es reforzado con tripa fresca de cordero.

Los lanzamientos se realizaron en la galería de tiro del Departamento de Balística y Grupo Técnico de Tecnología de la Policía Científica de Madrid, que contaba con un equipo de medición que permitía realizar el experimento en las condiciones más adecuadas.

Se han utilizado tres tipos de arcos distintos. Dos de ellos eran arcos industriales laminados, mientras que el tercero era una réplica del arco mesolítico danés de Holmegaard (Becker 1945). Los arcos fueron montados sobre un bastidor para impedir variaciones en la apertura. De esta forma, hemos podido estandarizar en todos los casos la apertura del arco $(40-50 \mathrm{~cm})$.

De los 58 disparos efectuados se han tomado dos mediciones, la primera al inicio del disparo y la segunda a una cierta distancia para controlar la pérdida de energía cinética. Así, el primer medidor se ha colocado a 1,10 m. del arco para controlar la velocidad inicial (Velocidad 1). El segundo medidor, que ha recogido la velocidad final (Velocidad 2), fue situado a 8,5 $\mathrm{m}$ del mismo. Las medidas, recogidas en $\mathrm{m} / \mathrm{sg}$, han sido transformadas en energía cinética (Ec0 para la energía inicial, Ec1 para la energía final y Ecr que marca la pérdida de energía entre el momento del disparo y un momento situado a la distancia elegida).

Se ha realizado un estudio de ANOVAS que permiten el análisis de la varianza buscando las diferencias significativas entre medias. Para poder utilizar los datos obtenidos del experimento se han convertido en variables categóricas tanto el peso como la longitud de la flecha. En el caso del peso, se agrupan las flechas en pesadas ( $\mathrm{H}=$ heavy) o ligeras 
( $L=$ light), dependiendo de si su peso es mayor o menor respectivamente de $30 \mathrm{gr}$. En cuanto a la longitud de la flecha, éstas son agrupadas en cortas ( $\mathrm{S}=$ short) o largas ( $\mathrm{L}=$ long), dependiendo de si el largo es mayor o menor respectivamente de $90 \mathrm{~cm}$ (Fig. 3).

La única variable que ha resultado significativa para la energía final (Ec1) ha sido el tipo de arco. Las flechas disparadas con ayuda del arco laminado de 40 libras presentan una Ec1 significativamente menor que las disparadas con el de 50 libras. Pero el arco de 40 libras de olmo sería, por otra parte, el que perdería menos energía entre los dos puntos en los que se ha medido la velocidad.

En cuanto al resto de las variables, se han observado diferencias aunque no son estadisticamente significativas. Sólo el número de plumas parece tener mayor importancia. Se observan diferencias para su interacción con la Ec0, pero no son estadísticamente significativas. En este sentido, las flechas con 3 plumas muestran una Ec0 menor que las emplumadas con 2. Por el contrario, no parece existir relación entre el peso de las flechas y la velocidad.

Así mismo, también muestran diferencias, aunque no significativas desde el punto de vista estadístico, y esta vez tanto para la energía cinética inicial como final, entre las flechas cortas y largas. En los dos casos, la Ec0 y Ec1 de las flechas cortas ( $\mathrm{S}=$ short), tiende a ser menor que la de las flechas más largas ( $\mathrm{L}=$ Long).
Aunque el aumento de la muestra permitiría confirmar si dichas variables influyen significativamente desde el punto de vista estadístico en la velocidad de la flecha, desde el punto de vista balístico los disparos efectuados con los arcos y las PAP han sido del todo satisfactorios en cuanto a trayectorias y efectividad.

Así mismo, para contrastar la eficacia cinegética de las de puntas de aletas y pedúnculos, tuvimos la oportunidad de realizar un programa experimental controlado de disparos sobre un sarrio (Márquez y Muñoz 2003). El experimento contó con un total de cinco flechas. Se emplearon astiles de madera de cedro industrial de $9 \mathrm{~mm}$ diámetro y una longitud, sin contar la punta, en torno a los $79 \mathrm{~cm}$ (Fig. 4).

Para el emplumado se colocaron tres plumas dispuestas en forma radial, equidistantes entre sí y fijadas por los dos extremos con tendón de caballo, mientras que el raquis se unió al astil con resina. El emplumado medía $15 \mathrm{~cm}$ de largo y se situó a 2,5 cm del extremo proximal de la flecha. Las plumas procedian de la parte superior derecha del ala de un alimoche y de un águila.

El culatín estaba incorporado en el propio astil, mediante el tallado de una ranura de tamaño suficiente. Una vez más tanto el culatín como la ranura para insertar la punta se realizaron a "contraveta" y se embotó ligeramente el extremo proximal pedúnculo para intentar evitar que el astil se rajara en el momento del impacto. Aun así, son fre-

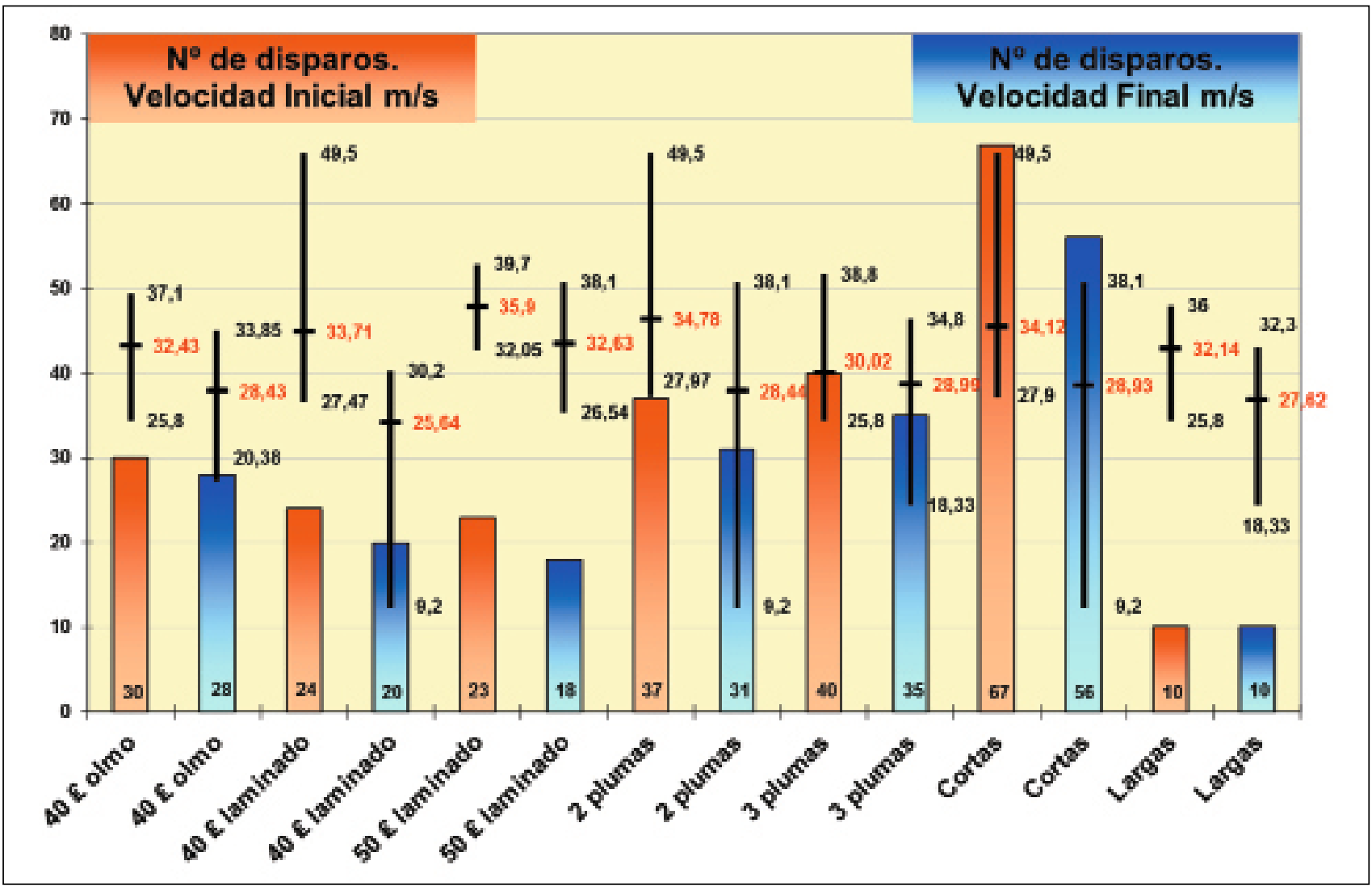

A Figura 3. Resultados de los lanzamientos con réplicas de puntas de aletas y pedúnculo realizadas resina de poliéster. 


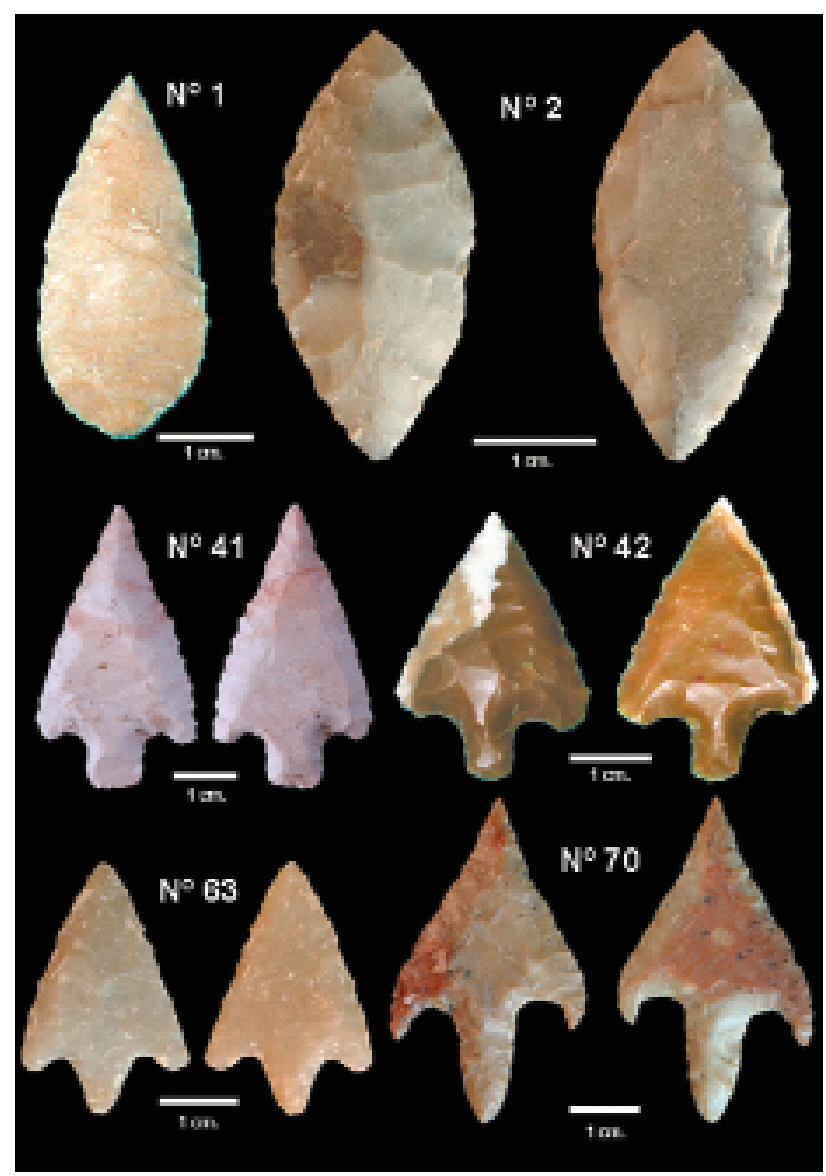

A Figura 4. Puntas de proyectil empleadas en la experimentación cinegética.

cuentes este tipo de fracturas en los astiles, de ahí la ventaja del uso del antefuste.

En los astiles se montaron dos puntas ovaladas de retoque plano y bifacial ( $n^{\circ} 1$ y 2 ) y cuatro puntas de aletas $y$ pedúnculo ( $n^{\circ} 41,42,63$ y 70 ), con una longitud que oscilaba entre los 48 y $32 \mathrm{~mm}$, un peso entre 2 y $5 \mathrm{gr}$ y un ángulo entre los 60 y $45^{\circ}$. Las puntas fueron fijadas al astil mediante ligaduras vegetales y una almáciga compuesta por resina de pino, cera de abeja y carbón como aglutinante (Fig. 5).

El peso en total de las flechas, ya montadas, oscilaba, entre 28 y 31 gr. Para dispararlas se utilizaron dos longbow simples realizados en madera de tejo de $163 \mathrm{~cm}$ de longitud y con una potencia de 50 libras. La distancia de tiro fue en todos los casos de $10 \mathrm{~m}$ por considerar ésta la idónea para la caza.

El sarrio recién muerto, una hembra vieja de sarrio de alrededor de 50 kilos, fue colocado inclinado sobre un terraplén de pendiente pronunciada. Se dispararon una a una todas las flechas. Tres de las puntas $\left(n^{\circ} 1,41\right.$ y 42$)$ se soltaron del astil y quedaron en el interior del animal al primer disparo. Ninguna de ellas tocó hueso. La $n .^{\circ} 2$ fue la única que ha podido ser lanzada 5 veces, y aunque impactó en hueso en al menos una de las ocasiones, no se partió. Dos

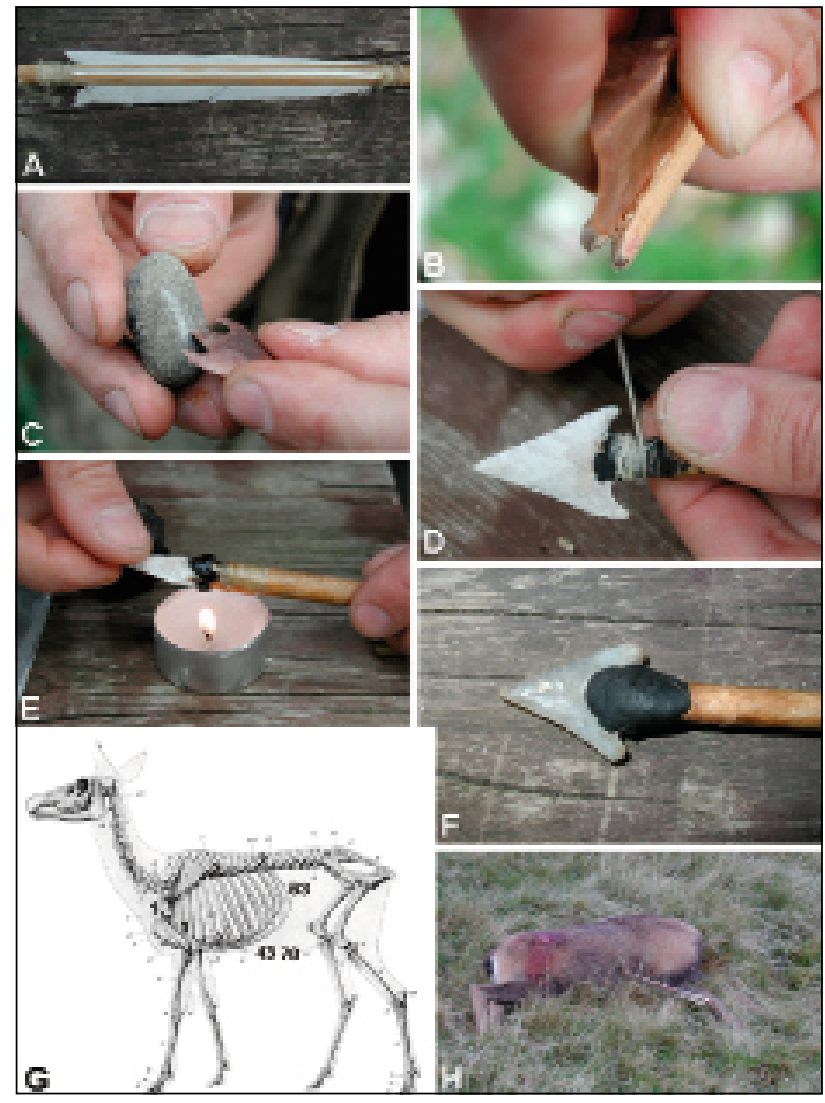

$\Delta$ Figura 5. Desarrollo de la experimentación cinegética. Sistema de emplumado: A. Preparación del culatín: B. Embotado del filo del pedúnculo del proyectil: C. Enmangue de la punta en el astil, atándola con tendón y fijándola con resina: D-F. Localización de los impactos de los proyectiles en el sarrio: G. Situación del sarrio durante los lanzamientos de las flechas: $\mathrm{H}$.

de las veces el tiro resultó alto y se ha clavó en el suelo. La n. 70 se clavó directamente en el suelo y no se volvió a lanzar para contrastar las marcas. Solo la punta $n^{\circ} 63$ se partió a la altura del pedúnculo que quedó inserto en el astil, mientras que el cuerpo de la flecha quedó dentro del animal y también se fracturó una aleta.

Para el análisis microscópico, una vez limpias todas las puntas, se utilizó un microscopio óptico de luz incidente y transmitida Olympus BX51 con un cambiador de aumentos de 100x a 500x, para la observación de pulimentos y estrías, y una lupa binocular Leica Wild MZ8 con cambiador de aumentos de 6,3x a 50x para desconchados y embotamientos.

Se ha constatado la existencia de estrías procedentes de la talla en la mayoría de las piezas. Aunque la mayor parte de dichos estigmas de carácter tecnológico desaparecen con los sucesivos retoques.

Las huellas producidas por enmangue de las puntas son menos comunes pero se han observado pulimentos de madera con estrias asociadas en algunas de ellas ( $n^{0} 1,2$ y 42 ). Si la punta no se encuentra firmemente sujeta se pueden producir este tipo de marcas producidas por la fricción. Así, encontramos un mayor número de fracturas en el pedúnculo 
cuanto mejor sea la sujeción. Aquí, en lugar de saltar la pieza entera tras el impacto, ésta se rompe, generalmente a la altura del pedúnculo. En nuestras puntas hemos observado este tipo de fractura solamente en la $n^{\circ} 63$.

Las fracturas debidas al impacto se producen sobre todo cuando el proyectil golpea con el hueso, y mucho menos frecuentemente si sólo atraviesan carne (Fig. 6). Sólo la punta $n^{\circ} 63$ tiene marcas de fracturas de carácter macroscópico. Hay estrías de impacto y trazos lineares de pulimento paralelos al eje longitudinal de la pieza. Este tipo de huella se produce cuando pequeños fragmentos de piedra desprendidos tras el choque entran en contacto con la superficie de la punta. Hay escasos puntos de pulimento "de carnicería", característico de los impactos en las piezas 2, 4 y 42 . Por último, la pieza que chocó contra el suelo, la n 70 , muestra la presencia en una de las caras de estrías producidas probablemente por el choque.

Este experimento ha demostrado la eficacia que debía tener este tipo de proyectiles para las actividades cinegéticas:

- El vuelo de todas las flechas tuvo una trayectoria rectilínea, similar a las flechas convencionales actuales.

- Las puntas no se fracturaron al primer impacto, salvo la $n^{\circ} 63$, incluso las que se clavaron en la tierra o en el hueso.

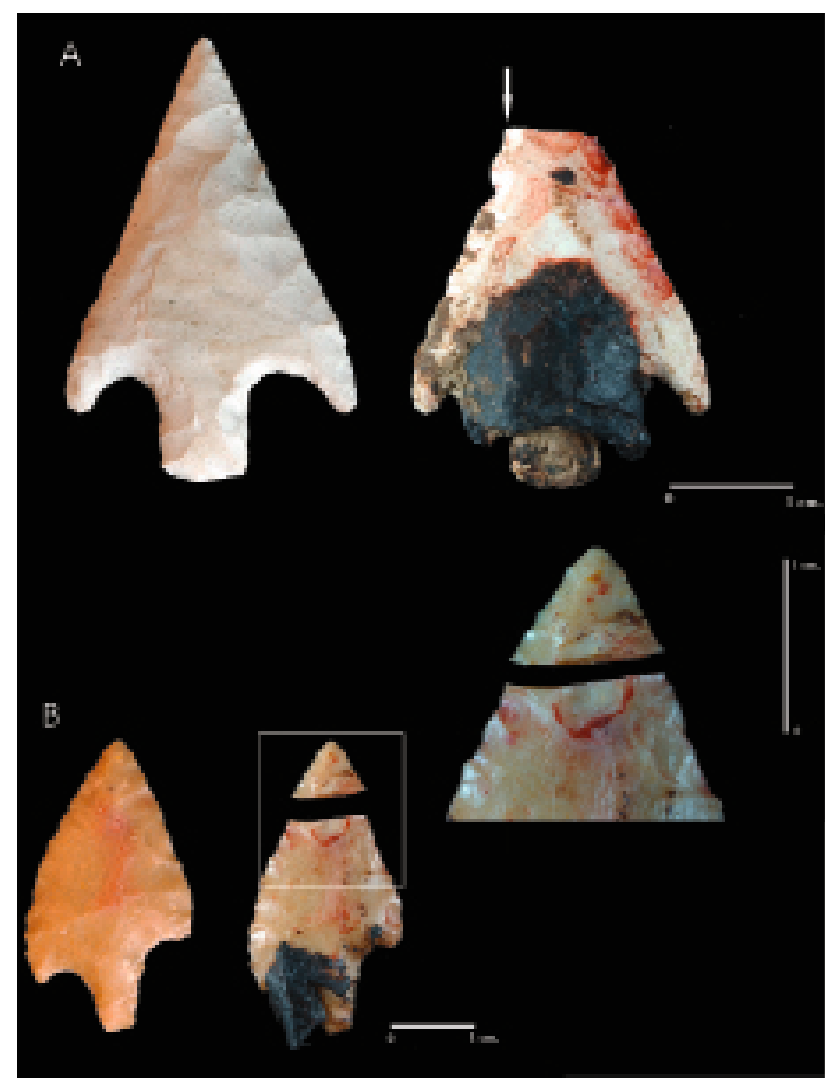

A Figura 6. Puntas de pedúnculo y aletas experimentales de estilo solutrense tras el impacto. A. Burinación. B. Doble fractura en lengüeta.
- Ninguna flecha rebotó y la capacidad de penetración en el animal osciló entre los 10 y los $30 \mathrm{~cm}$.

Es evidente que el trabajo de F. J. Muñoz y B. Márquez lo hemos tratado con más detalle que el de J. M. Geneste y $H$. Plisson por un motivo tan sencillo como es el que los dos primeros son firmantes de este trabajo y por lo tanto tenemos información de primera mano mucho más detallada. En todo caso, a partir de ambos trabajos experimentales el lector puede inferir cuáles son los elementos que influyen en la efectividad de las puntas experimentales, así como en el desarrollo de las fracturas de impacto y el de otras huellas microscópicas como las estrías. Sin embargo, un aspecto interesante a resaltar es el hecho de que no todas las puntas lanzadas llegan a presentar modificaciones macro o microscópicas. El elemento que más influye a este respecto es si entra en contacto con las partes esqueléticas del animal o en aquellos tiros errados conecta con alguna materia dura como una piedra, un árbol, etc. Si las puntas entran en el animal y no tocan ningún hueso, difícilmente se fracturan o como mucho se generan pequeñas melladuras no diagnósticas.

Este aspecto es relevante en tanto que las fracturas de impacto son por antonomasia el elemento más diagnóstico para definir si una punta se empleó o no como proyectil. La presencia de estrías es un elemento complementario que puede reforzar esta hipótesis. En aquellas puntas arqueológicas en las que no habiendo fracturas de impacto hay estrias, debemos valorar ciertos factores para determinar si fueron generadas por su uso como elementos de proyectil. $Y$ es que a menudo muchas de las estrías documentadas en el utillaje lítico son resultado de alteraciones ante y postdeposicionales. Múltiples acciones como el contacto con la superficie de la punta cuando se elaboró y se enmangó, su manipulación durante su exhumación y su estudio, la forma como se almacenaron (habitualmente juntas en una misma bolsa o caja), entre otras, pueden generar estrías que no se diferencian de las generadas por impacto de proyectil (Fig. 7).

En definitiva, mientras las fracturas de impacto nos confirman que las puntas se emplearon como elementos de proyectil, su ausencia no conlleva que no se usaron. Si tales puntas durante su utilización no entraron en contacto con el esqueleto del animal, muy probablemente no presente ni la más mínima fractura, aún habiéndose tirado incluso varias veces.

\section{EL ANÁLISIS FUNCIONAL DE CONTEXTOS SOLUTRENSES PENINSULARES}

Son pocos los contextos solutrenses donde se han realizado estudios traceológicos. Ello puede deberse a dos factores interconectados: el desinterés por hacer este tipo de 


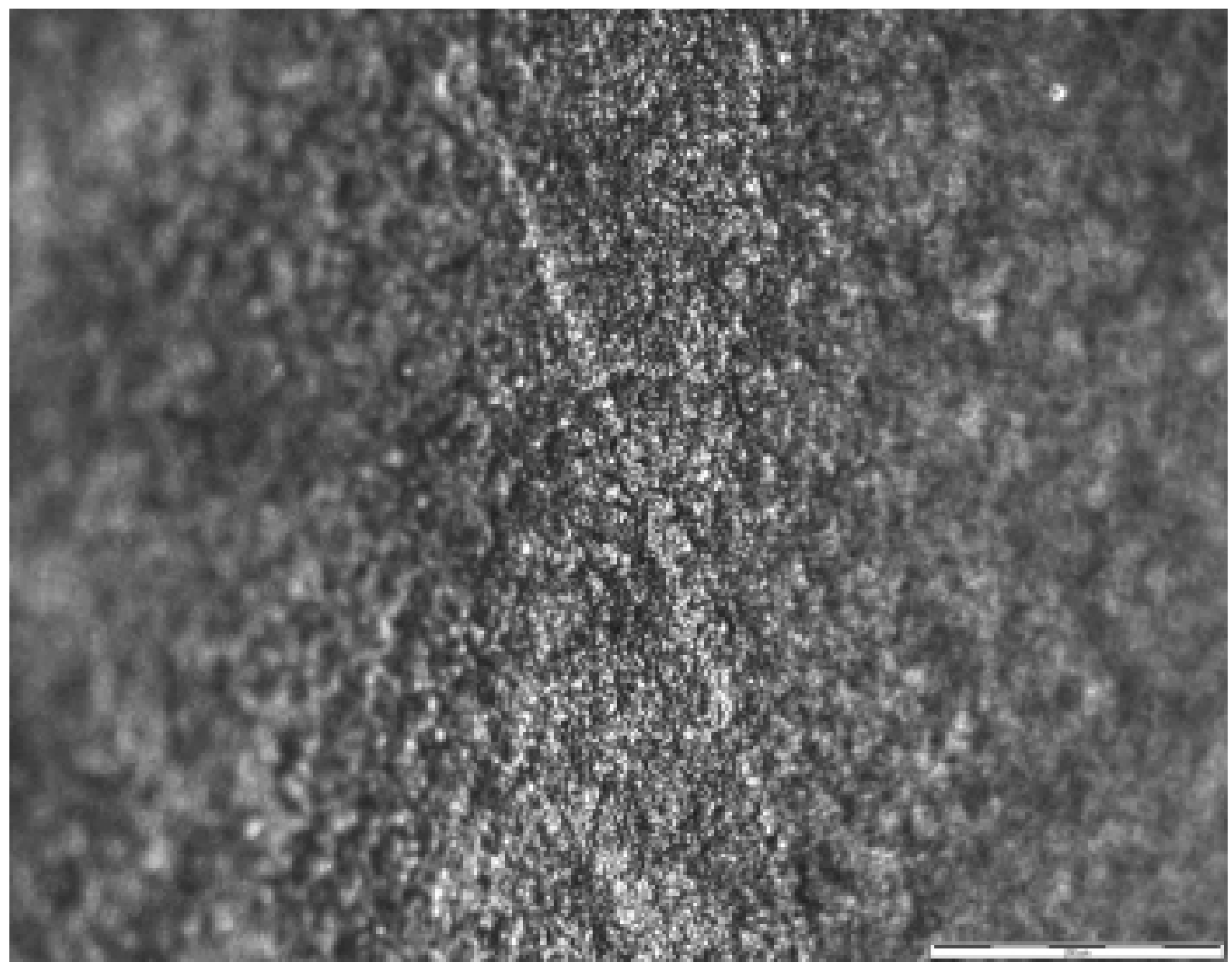

A FiguRa 7. Estría similar a las producidas por impacto en una punta experimental antes de ser disparada. Fotografía 100x.

análisis por parte de los directores de las excavaciones e investigadores que estudian yacimientos de este periodo, y el propio desinterés por parte de los traceólogos.

A este respecto, en estos últimos años uno de nosotros (JFG) ha tenido la oportunidad de abordar el análisis traceológico de un conjunto de puntas solutrenses procedentes del asentamiento de Vale Boi, Portugal (Fig. 8). Se trata de un yacimiento situado al oeste de la región del Algarve, próximo a la población de Vila do Bispo (Bicho et al. 2003). Las numerosas campañas de excavación iniciadas en el año 2000 han permitido reconocer varias áreas con ocupaciones humanas desde el Gravetiense hasta el Magdaleniense (más detalles en Cascalheira et al. en este volumen).

Entre los materiales de los niveles solutrenses estudiados (datados entre el 25.0 ka y el 20.3 ka cal BP), se documenta un conjunto de puntas de distinta morfología: puntas de Vale Comprido, de cara plana, de laurel, con aletas y pedúnculo y con escotaduras (Gibaja y Bicho, en prensa). No entraremos a exponer los resultados del análisis traceológico obtenido del conjunto utillaje lítico, sino solamente del de las puntas, objeto de este artículo.
De manera muy general, decir que el análisis traceológico se ha realizado sobre un total de 22 puntas con diferentes morfologías: puntas de pedúnculo y aletas, pequeñas hojas de laurel, puntas con muesca y alguna punta de cara plana. A éstas hay que sumarles 7 fragmentos que no podemos atribuir a una forma precisa y 8 preformas de puntas (Gibaja y Bicho en prensa). De todo este conjunto 16 presentan fracturas de impacto por su uso como proyectiles. El resto corresponden a las citadas preformas de puntas no usadas o a puntas que hemos catalogado como no analizables por estar muy alteradas.

Las huellas que hemos observado son preferentemente fracturas de impacto cuya morfología es en buril o con terminaciones abruptas o reflejadas (step and hinge fractures). Por otro lado, en algunas de estas puntas también hemos registrado estrías producidas probablemente en el momento en que impactan con el esqueleto del animal (Fig. 8). No obstante, sobre algunas de estas estrias teniamos dudas sobre su origen, ya que el material estaba muy alterado, especialmente por el lustre de suelo. De lo que estábamos seguros es que no se habian producido durante su exhumación 


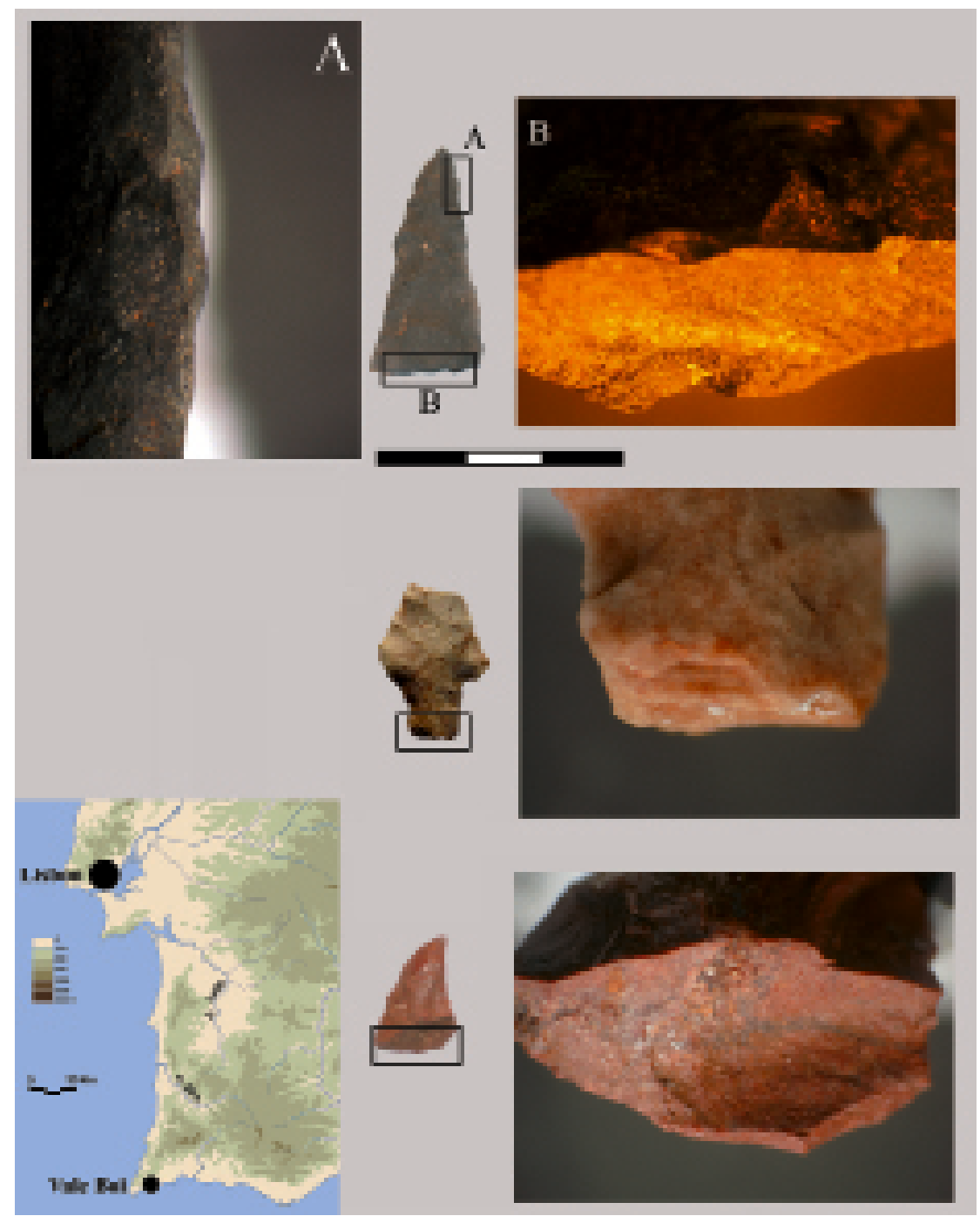

FIgURA 8. Localización del asentamiento de Vale Boi (Portugal). Fracturas de impacto en las zonas apicales o en los pedúnculos de algunas de las puntas de Vale Boi.

y almacenamiento porque todas las piezas del yacimiento fueron tratadas con sumo cuidado, limpiadas simplemente con agua (sin utilizar cepillos) y guardadas individualmente sin siglar en bolsas de plástico.

Las fracturas en $90^{\circ}$ halladas en otras puntas no las hemos podido relacionar con su uso como proyectiles, ya que también pueden producirse por pisoteo, durante los procesos de talla, etc. Esto no significa que no estuvieran usadas, sino que no tenemos elementos diagnósticos suficientes como para decidir si tales fracturas son de impacto o generadas por otros factores no funcionales. Eso mismo sucede con las puntas no fracturadas. Como hemos apuntado, en los experimentos se ha observado que si las puntas no tocan hueso, habitualmente no se fracturan.

Aunque hay algunas puntas enteras, en la mayoria se aprecian fracturas en las zonas apicales y/o en las aletas. También hemos documentado pequeños fragmentos apicales que seguramente se quedaron depositados dentro de los animales cuando se extrajeron de la presa. Esta variabilidad en la localización de las fracturas nos hace pensar que los procesos de elaboración, extracción, reparación y substitu- ción se realizaban en el propio asentamiento. Cabe recordar que por lo general la mayor inversión de tiempo de trabajo se dedica a la elaboración de los astiles, por ello es bien conocido desde la arqueología experimental y la etnografía como sistemáticamente las personas que cazan recuperan los astiles. Un buen astil, equilibrado, con un peso idóneo y recto conlleva a menudo mucho más trabajo y pericia que la elaboración de una punta sobre lasca, más aún si las técnicas empleadas son simples.

Finalmente, queremos destacar la presencia de una punta en cuyo lateral izquierdo no retocado se aprecian huellas producidas posiblemente por el corte de piel seca (Fig. 9). Esta circunstancia se debe, sin duda, a un reutilización, ya sea antes de configurar la punta o cuando ésta ya estaba plenamente realizada. No podemos asegurar la secuencia de qué fue primero, si el corte de piel o la punta, porque las huellas se encuentran en uno de los laterales retocados y los hemos detectado puntualmente en ciertas zonas, no a lo largo de todo el filo. El estado de conservación de la pieza y los procesos implicados en su elaboración y quizás reavivados, nos impiden tener elementos sólidos para definir tal temporalidad. 


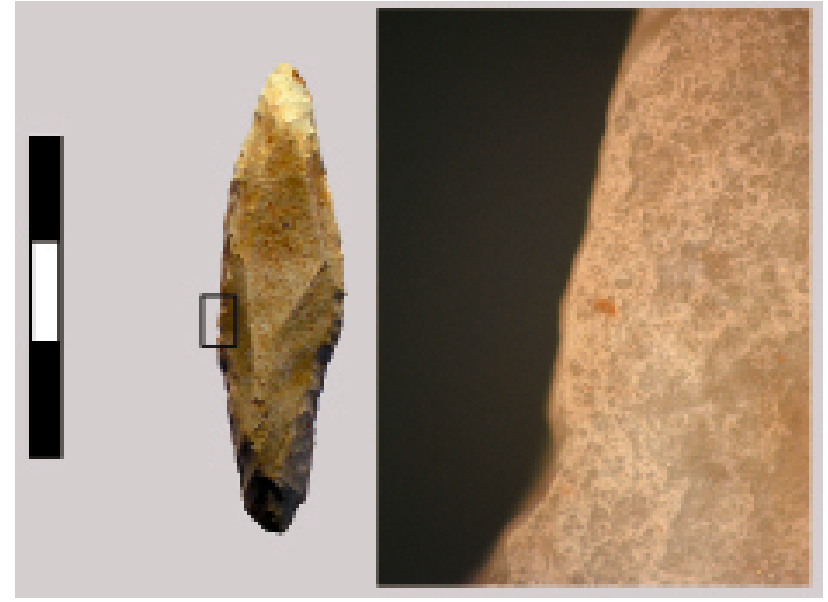

A Figura 9. Punta solutrense de Vale Boi en cuyo lateral izquierdo se aprecia una fuerte abrasión y redondeamiento producto probablemente del corte de piel seca. Foto micro a $200 X$.

En todo caso, nos parece enormemente interesante esta pieza, en tanto que desde los análisis morfológicos habituales difícilmente se piensa que los soportes sobre los que se confeccionaron las puntas, se destinaron inicialmente a otras actividades. En todo caso, otros investigadores han observado procesos de reciclado. Es el caso de Corchón (1995), cuando afirma que en el yacimiento Cueva de las Caldas (Oviedo, Asturias) alguna punta foliácea se ha transformado posteriormente en buril, o P. Foucher en el yacimiento francés de Coustaret donde algunas piezas bifaciales se han transformado en buriles o muescas (Foucher et al. 2002). Esto daría una idea de la reutilización puntualmente de algunas de las puntas solutrenses.

Recientemente hemos empezado a abordar nuevos contextos solutrenses, como es el caso de la Cueva del Higueral de Valleja, en Cádiz (Giles Pacheco et al., cuya comunicación fue presentada en este congreso) o Finca Doña Martina, en Murcia (Ignacio Martín, com. pers). Sin embargo, estamos en un momento inicial del estudio y los datos son por el momento poco relevantes como para ser publicados.

\section{A MODO DE RESUMEN}

A lo largo de la elaboración de este trabajo hemos podido observar que las puntas solutrenses han atraído enormemente la atención de los investigadores. Sus diferentes formas, tamaños, técnicas de elaboración y distribución han sido los ingredientes perfectos con los que darles un contenido cronológico y cultural. A partir de ahí son innumerables los trabajos que se han escrito en relación a qué puntas son de qué periodo, de qué sustrato se originan, en qué territorios se han documentado, etc.

En el primer apartado de este artículo se puede inferir esa prolija bibliografía que se ha generado a partir del interés que ha generado el estudio morfológico de las puntas solutrenses. Sin embargo, ante este complejo panorama tipológico, hemos observado un conjunto de aspectos que nos resultan difíciles de explicar. A nivel contextual, hay un déficit evidente de dataciones sin calibrar en BP realizadas en secuencias solutrenses. La única excepción lo debemos buscar en los trabajos de S. Corchón para el Cantábrico que además presenta las dataciones en cal BC.

Desde el punto de vista de la función de los instrumentos, se ha hecho evidente en este artículo que en relación a las puntas han sido, son $y$, pensamos que seguirán siendo durante mucho tiempo, un referente los trabajos realizados por J. M. Geneste y H. Plisson, por un lado, y F. J. Muñoz y B. Márquez, por otro. Sin embargo, hay un déficit experimental evidente cuando repasamos las distintas variedades de puntas que forman parte del horizonte solutrense. Los trabajos citados se han centrado exclusivamente en las puntas con muescas o en las puntas de pedúnculos y aletas. Es verdad que algunos de los resultados experimentales pueden extrapolarse a otros tipos de puntas, como por ejemplo la forma que tienen las fracturas de impacto diagnósticas, pero otros requieren de programas experimentales específicos que nos ayuden a comprender su efectividad, su capacidad de inserción, la distancia que podian recorrer en base al tipo de arco, los animales que más fácilmente podían ser cazados, etc.

Por otra parte, la escasez de estudios traceológicos es tan alarmante, que se hace difícil entender las razones por las cuales los investigadores y especialistas apenas han prestado interés a un periodo tan sugerente para comprender el desarrollo de nuestra especie, y a un instrumental que a nivel técnico constituye el cenit de la perfección. Es perentorio tratar contextos desde una perspectiva amplia de la función del utillaje, huyendo de análisis dedicados a pequeñas colecciones.

Estamos seguros que en los próximos años el interés de nuevos traceólogos irá supliendo este problema. Hay unos yacimientos fantásticos, con secuencias cronológicas interesantes y con unos materiales que están esperando a ser analizados. Aunque habitualmente se dice que quedan muchas cosas por hacer, en lo referente al solutrense y a los estudios sobre la función de los útiles, podemos acabar diciendo que queda más bien todo por hacer.

\section{AGRADECIMIENTOS}

Queremos agradecer la ayuda, el asesoramiento y la crítica al Dr. Hugues Plisson en relación a la comunicación que presentamos en el congreso del que nace esta publicación. Sin duda, sus opiniones han enriquecido y mejorado este artículo. Igualmente, agradecer al Dr. Nuno Bicho el permitirnos consultar información inédita de las puntas solutrenses del asentamiento de Vale Boi. • 


\section{BIBLIOGRAFÍA}

AlCARAZ, M. 2007: "El Ateriense del Norte de África y el Solutrense peninsular: ¿contactos transgibraltareños en el Pleistoceno superior?". Munibe 58: 101-126

AUBRY, T. 1991: L'explotation des ressources en matières premières lithiques dans les gisements solutréens et badegouliennes du basin versant de la Creuse (France). Thèse de Doctorat Université de Bordeaux. Bordeaux.

Aubry, T., Walter, B., Robin, E., Plisson, H. y BenhabdelHadi, M. 1998: "Le site solutréen de plein-air des Maîtreaux (Bossay-sur-Claise, Indre-etLoire): un faciès original de production lithique". Paléo 10: 163-184.

Aubry, T., Walter, B., AlmeidA, M., Lllard, M. y Neves, M. J. 2004: "Approche fonctionnelle des dites dits d'atelier: l'exemple des occupations solutréennes et badegouliennes des Maîtreaux (Indre-et-Loire, France)". Approches fonctionnelles en Préhistoire, Actes du XXV Congrès Préhistorique de France, Nanterre 2000. Société Préhistorique Française: 249-263.

Aubry, T., Almeida, M., Mangadollach, J., Neves, M-J., Peyrouse, J-P. y WalTER, B. 2007: "Mythes et réalités préhistoriques: apport du site des Maîtreaux à la définition de la variabilité des productions lithiques au Solutréen". En J. Evin (dir): Un siècle de construction du discours scientifique en Préhistoire, 3: 105-124.

BANKS, W.E. 1996: Toolkit Structure and Site Use: Results of a HighPower Use-Wear Analysis of Lithic Assemblages from Solutré (Saône-et-Loire), France. PhD Thesis - University of Kansas.

BICHO, N., StineR, M; LINDLY, J. y FeRRING, C.R. 2003: "Preliminary results from the Upper Paleolithic site of Vale Boi, Southwestern Portugal". Journal of Iberian Archaeology 5: 51-65.

BREZILLoN, M. 1983: La dénomination des objets de pierre taillé. IVè Supplément Gallia Préhistoire. CNRS.

Chadelle, J., Geneste, J. y Plisson H. 1990: "Processus fonctionelles de formation des assemblages technologiques dans les sites $\mathrm{du} \mathrm{Pa}-$ léolithique superieur. Les pointes de projectiles lithiques du Solutréen de la grotte de Combe Sanière (Dordogne, France) ". 25 ans d'etudes technologiques, Actes des XI Rencontres Internationales d'Archéologie et d'Histoire d'Antibes. APDCA Ed.: 275-288.

Corchón, S. 1995: "La cueva de Las Caldas (Priorio, Oviedo). III. Resultados preliminares de las excavaciones (Campañas 1991-1994)". Excavaciones Arqueológicas en Asturias 1991-1994 3: 45-60.

CoRChón, M. S. y CARDoso, J. L. 2005: "Reflexiones sobre el Solutrense portugués: a propósito de la industria Paleolítico superior de Correio-Mor (Loures)". Zephyrvs LVIII: 89-110.

CORCHÓN, M.S. 2008: "El solutrense y el arte rupestre en Portugal. Reflexiones acerca de la obra de 0 . Da Veiga Ferreira y su proyección actual". Homenagem a Octávio da Veiga Ferreira. Estudos Arqueológicos de Oeiras 16: 183-234.

FouCHER, P. 2007: "Les territoires solutréens des Pyrénées-Cantabres, d'après les armatures foliacées et la circulation des matières premières". En N. Cazals, J.E. González Urquijo y X. Terradas (coords): Frontières naturelles et frontières culturelles dans les Pyrénées préhistoriques: 279-300. Universidad de Cantabria.

Foucher, P., SIMONET, R. y JARRY, M. 2002: "L'atelier de taille Solutréen de Coustaret(Saint-Martin, Hautes-Pyrénées)". Paléo 14: 49-62,

Hugot, H. S. 1957: "Essai sur les armatures de pointes de flèches du Sahara". Libyca Anthropological: 89-236.

GeneSTE, J. M. y PLISSON, H. 1986: "Le Solutréen de la Grotte de Combe Saunière I (Dordogne): première approche palethnologique". Gallia Préhistoire 29, 9-27.

- 1990: "Technologie fonctionnelle des pointes solutréennes: une approche systématique". En J.K. Kozlowski (dir.): Feuilles de pierre. Les industries à pointes foliases du Paléolithique supériur européen. Actes du Colloque de Cracovie. ERAUL 42: 293-320.

- 1993: "Hunting technologies and Human Behavior: Lithic analysis of Solutrean Shouldered Points". En H. Knecht, A. Pike-Tay y
R. White (Eeds.): Before Lascaux: The Complex Record of the Early Upper Palaeolithic. CRC Press: 117-135.

GIBAJA, J. F. y BICHO, N. en prensa: "Provenience, technology, morphology and the use of Proto-Solutrean and Solutrean points from Vale Boi (Algarve, southern Portugal): preliminary results". Le Solutréen...40 ans après Smith' 66.

Maillo, J. M. 1999: "Esquemas operativos y conocimiento técnico: el caso del yacimiento solutrense de Vale Almoinha (Torres Vedras, Portugal)". Espacio, Tiempo y Forma, Serie I, Prehistoria y Arqueología 12: 185-214.

MÁRQuez, B y Muñoz, F. J. 2003: "Arqueria Prehistórica: Aproximación experimental sobre sistemas de enmangue y propulsión de las puntas de aletas y pedúnculo del Solutrense extracantábrico". XXVII Congreso Nacional de Arqueología. Bolskan 18: 147-154.

- 2008: "Barbed and tanged arrowhead of extra-Cantabrian Solutrean: experimental programme". En L. Longo y N. Skakun (eds.): Prehistoric Technology 40 years later: Functional Studies and the russian legacy. Verona. BAR Internacional Series 1783. 0xford: 379-382.

MuÑOZ, F. J. 1998: "Metodología para el estudio de las puntas ligeras de proyectil del Solutrense extracantábrico". Espacio, Tiempo y Forma, Serie I. Prehistoria y Arqueología 11: 83-108.

- 1999: "Algunas consideraciones sobre el inicio de la arquería prehistórica". Trabajos de Prehistoria 56 (1): 27-40.

- 2000: Las puntas ligeras de proyectil del Solutrense extracantábrico. Análisis tecnomorfológico e implicaciones funcionales. Colección Aula Abierta.UNED, Madrid.

- 2010: "El Paleolítico superior en Europa". En S. Ripoll (Coord.): Prehistoria I. Las primeras etapas de la humanidad. Madrid.

MuÑoz, F. J. y MÁrouez, B. 2006: Las puntas de aletas y pedúnculo del Solutrense peninsular: un programa experimental. En J.L. Sanchidrián, A. M. a Márquez y J. M. Fullola (eds). IV Simposio de Prehistoria de la Cueva de Nerja: La cuenca mediterránea durante el Paleolítico superior. La cuenca mediterránea durante el Paleolítico superior. Reunión de la VIII Comisión del Paleolítico superior de la UISPP. Nerja: 234-246.

PLISSON, H. y GeNeSTE; J. M. 1989: "Analyse technologique des pointes à cran solutréennes du Placard (Charente), du Fourneau du Diable, du Pech de la Boissière et Combe Saunière (Dordogne)". Paléo 1: 65-106.

RASILLA, M. DE LA 1989: "Secuencia y crono-estratigrafia del Solutrense cantábrico". Trabajos de Prehistoria 46: 35-46.

RASILLA, M. DE LA y LLANA, C. 1995: "Del Solutrense en la Península Ibérica: El Solutrense en Portugal y los inicios del Solutrense". Trabalhos de Antropología e Etnología 30 (4): 89-103.

RIPOLL, S. 1994: "El yacimiento de La Cueva de Ambrosio: nuevas aportaciones al solutrense de la Peninsula Ibérica". Homenaje al prof. Miguel Guirao (Vélez-Rubio, Almeria): 55-78.

SмIтH, P. H. 1966: Le Solutréen en France. Delmas. Bordeaux.

SolER, N. 1994: "Le Solutréen en Catalogne". Le Solutréen en Péninsule Iberique. Musée Départamental de Solutré: 38.

Sonneville-Bordes, D. DE y Perrot J. 1954-1956: "Lexique typologique du Paléolithique supérieur". Bulletin de la Société préhistorique française 51: 327-335; 52: 76-79; 53: 408-412; 53: 547-549.

StrauS, L. G. (2001): "Africa and Iberia in the Pleistocene". Quaternary International 75: 91-102.

Straus, L. G. y Gonzalez Morales, M. R. 2009: "The Miron Cave: a preliminary description of Solutrean occupations in El Mron cave (Ramales de la Victoria, Cantabria)". Munibe 60: 117-137.

TifFaGom, M. 1999: "Testimonios de tratamiento térmico en hojas de laurel del Solutrense superior de la Cova del Parpalló (Gandia, Valencia)". Archivo de Prehistoria Levantina XXIII: 67-84.

- 2004: De la Pierre à l'Homme: enquête technologique sur la dynamique évolutive des groupes solutréens de la Cova de Parpalló (Gandia, Espagne). Thèse de doctorat, Université de Paris I.

- 2005: "El Solutrense de facies ibérica o la cuestión de los contactos transmediterráneos (Europa, África) en el Último Máximo Glaciar". En J. L. Sanchidrián, A. M. Márquez y J. M. Fullola (eds.): IVSimposio 
de Prehistoria Cueva de Nerja. La Cuenca Mediterránea durante el Paleolitico superior, 38.000-10.000 años: 60-77.

- 2006: De la Pierre à l'Homme. Essai sur une paléoanthropologie solutréenne. ERAUL 113. Université de Liège. Liège.

ZıเнÃo, J. 1994: "La séquence chrono-stratigraphique du solutréen portugais". Férvedes 1: 119-129.

- 1997: O Paleolítico Superior da Extremadura Portuguesa. Ediçoes Colibrí.
ZILHÃO, J. y AUBRY, TH. 1995: "La pointe de Vale Comprido et les origines du Solutréen". L'Anthropologie 99 (1): 125-142.

Zillião, J., AubRY, TH. y AlmeIDA, F. 1999: "Un modèle technologique pour le passage du Gravettien au Solutréen dans le Sud-Ouest de I'Europe". En D. Sacchi (ed.): Les faciès leptolithiques du nordouest méditerranéen: milieux naturels et culturels. XXIVe Congrès Préhistorique de France. Carcassonne, 26-30 Septembre 1994: 165-183. 